\title{
Biology of the Root-Attacking Moth, Isoceras sibirica Alpheraky
}

\author{
Zhixiong Liu ${ }^{1}$, Hongxia Liu ${ }^{1}$, Jintong Zhang ${ }^{1} \&$ Xupeng Chen ${ }^{1}$ \\ ${ }^{1}$ Institute of Chemical Ecology, Shanxi Agricultural University, Taigu, Shanxi, China \\ Correspondence: Jintong Zhang, Institute of Chemical Ecology, Shanxi Agricultural University, Taigu, Shanxi, \\ China. Tel: 86-0354-628-6879. E-mail: zhangjintong@126.com
}

Received: November 8, 2014 Accepted: December 7, 2014 Online Published: January 15, 2015

doi:10.5539/jas.v7n2p125

URL: http://dx.doi.org/10.5539/jas.v7n2p125

\begin{abstract}
The root-attacking moth, Isoceras sibirica Alpheraky (Lepidoptera: Cossidae), is a pest of the food crop Asparagus officinalis Linn, and can seriously affect yield. Data for this study were collected from both the laboratory and in the field over a 3-year period (2009 - 2011). Periods for egg incubation and pupal stage ranged from $24.49 \pm 4.92$ to $28.82 \pm 4.35,19.79 \pm 4.11$ to $21.32 \pm 3.46$ days, respectively. Larval weight during the developmental period was described by the equation: $y=0.0109 \mathrm{e}^{0.1888 x}$. An average longevity of 6.3 days was observed for male and 5.1 days for female adults. A forewing wingspan of $52.4 \pm 0.83 \mathrm{~mm}$ and $45.2 \pm 0.89 \mathrm{~mm}$ was observed for females and males, respectively. This study provides a basis for biological pest control of Isoceras sibirica.
\end{abstract}

Keywords: biology, Isoceras sibirica, life cycle, asparagus

\section{Introduction}

Due to the excellent conditions for the cultivation of asparagus, China was the largest producer of asparagus in the world in 2010, followed by Peru and Germany (National Agricultural Statistics Service, 2006). Asparagus farming therefore contributes significantly to the local economy. Isoceras sibirica Alpheraky (Lepidoptera: Cossidae), a destructive pest, is widely distributed in asparagus farms in China. I. sibirica larvae burrow into the root crowns, causing destruction of the freshly planted asparagus. This damage seriously affects growth and total asparagus yield. The larvae of I. sibirica grow within the roots of asparagus, making control difficult. At present, the main control method is the broad use of chemical pesticides. Year by year, long-term and heavy application of pesticides has resulted in serious environmental pollution, which can potentially compromise human health. Although strenuous efforts have been made to control the moths (Guoqi et al., 2010; Hongxia, Yujie, \& Jintong, 2010; Gaochuan et al., 2013); however, their biology has been studied little. Such biological insight would facilitate the formulation of effective management strategies (Kioko, Raina, \& Mueke, 2000), and is therefore the basis of this study.

\section{Methods}

This study was conducted both in the laboratory and in the field of Shanxi province, North China, which lies between latitudes $34^{\circ} 42^{\prime} \mathrm{N}$ and $40^{\circ} 42^{\prime} \mathrm{N}$, longitudes $110^{\circ} 24^{\prime} \mathrm{E}$ and $114^{\circ} 42^{\prime} \mathrm{E}$ altitude, and is $1000 \mathrm{~m}$ above sea level. Experiments conducted in the laboratory focused on the morphological structure of eggs, larvae, pupae and adults of I. sibirica. The field experiments were carried out during 2009, 2010 and 2011 in Shanxi.

\subsection{Egg Clusters and Incubation Period}

To determine egg size, 1000 eggs from six I. sibirica female moths were measured under a stereomicroscope using an ocular micrometer (Mbahin, Raina, Kioko, \& Mueke, 2012). The average length of 100 freshly laid egg clusters was determined using a Vernier calliper. An electronic balance was used to determine egg weight. Incubation periods were determined for 100 egg clusters, which were laid daily and marked. Eggs were monitored daily over 40 days and hatching times were recorded for each egg.

\subsection{Larval Period}

After hatching, larvae were transferred to separate asparagus plants and reared. The larval period was determined by observing the first through seventh instars of 100 cohorts of $I$. sibirica larvae until they emerged. The number of instars was calculated by visual observation of discarded exuviae (Mbahin et al., 2007; Schmidt, Campbell, \& Trotter, 1977). Larval weight during the developmental period is presented in Figure 1. 


\subsection{Pupal Period}

To measure the pupal period, spinning dates of 125 cocoon nests were recorded prior to transfer to an open sleeve $(50 \times 45 \times 45 \mathrm{~cm})$ until the adults emerged.

\subsection{Adults}

The life span of male and female moths was measured from the point at which larvae became viable. The moths were deposited into a wooden cage $(100 \times 100 \times 100 \mathrm{~cm})$ with nylon screens mounted on all four sides and a door on one side (Gothilf, 1968). Wingspan, as determined by the maximum distance between the tips of each forewing, was measured using a Vernier caliper.

\subsection{Data analysis}

Mean values were compared using a t-test (Peacock, \& Worner, 2008) or chi-square (Moses, Emerson, \& Hosseini, 1984). The SPSS 17.0 software package was used for data analysis. The degree of significance is shown as follows:

*: significant $(\mathrm{P}<0.05)$;

$* *$ : highly significant $(\mathrm{P}<0.01)$;

ns: not significant $(\mathrm{P}>0.05)$.

\section{Results}

\subsection{Egg Clusters}

The egg of $I$. sibirica is oval in shape, measures $1.96 \pm 0.02 \mathrm{~mm}$ at the major axis and $0.73 \pm 0.02 \mathrm{~mm}$ at the minor axis $(n=79)$. Eggs weigh an average of $0.84 \pm 0.003 \mathrm{mg}(\mathrm{n}=68)$, with regular hexagon ridges projecting upward. They are white in color, but become brown prior to hatching. The eggs are usually laid in clusters on the epidermis of asparagus stems. The mean number of freshly laid eggs in a cluster was $204 \pm 6(n=25)$. The incubation period ranged from 24 to 28 days. Mean incubation periods are shown in Table 1 .

Table 1. Mean ( \pm SD) incubation period (days) of I. sibirica in the asparagus field (2009-2011)

\begin{tabular}{lll}
\hline \multirow{2}{*}{ Year } & \multicolumn{2}{c}{ Isoceras sibirica Alpheraky } \\
\cline { 2 - 3 } & $\mathrm{n}$ & Incubation period (days) \\
\hline 2009 & 17 & $28.82 \pm 4.35$ \\
2010 & 23 & $26.30 \pm 5.18$ \\
2011 & 29 & $24.49 \pm 4.92$ \\
\hline
\end{tabular}

n: number of egg clusters.

\subsection{Larvae}

Newly emerged larva chew a small cavity, approximately $0.5 \mathrm{~mm}$ in diameter, into the stem and crawl down the stem to the root, which is typically $2-3 \mathrm{~cm}$ below the soil surface. Based on our observations, the larvae are gregarious from the first to the seventh instars. Direct observation of expelled exuviae by larvae reared through the larval stage indicated that there are six molts in the period from hatch to pupation. From the first larval instar until pre-pupa, young larvae grew from $1.8 \mathrm{mg}$ to more than $4,600 \mathrm{mg}$. Developmental data are presented in Figure 1 . The equation used to determine the curve is showed as $y=0.0109 \mathrm{e}^{0.1888 \mathrm{x}}$.

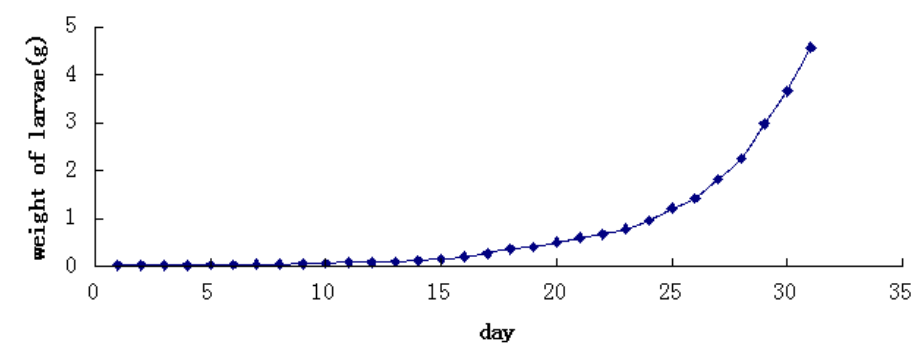

Figure 1.The developmental tendency of weight of larvae 


\subsection{Pupa}

After the larvae period is complete, mature larvae leave the asparagus in search of a convenient place to pupate. The cocoons averaged $8 \mathrm{~cm}$ in length and $1.5 \mathrm{~cm}$ in diameter and were gray in color. Within the cocoon, the larvae remained quiescent in a pre-pupa stage for 3 to 5 days before pupating. Cocoon construction and the pre-pupa stage required between 5 to 10 days, depending upon the ambient temperature. The length and width of male pupae ranged from 1.7 to $2.8 \mathrm{~cm}$ (mean $2.2 \pm 0.27)$ and 0.6 to $1 \mathrm{~cm}$ (mean $0.77 \pm 0.10)(\mathrm{n}=43$ ), while the length and width of female pupae ranged from 2.2 to 3.2 (mean $2.6 \pm 0.28$ ) and 0.6 to $1.2 \mathrm{~cm}$ (mean $0.84 \pm 0.12$ ) $(\mathrm{n}=38)$, respectively. There was a highly significant difference between the lengths and widths of the two sexes. The weight of the male pupae ranged from 0.23 to $0.47 \mathrm{~g}$ (mean $0.35 \pm 0.06$ ), whereas female pupae weight ranged from 0.27 to $0.56 \mathrm{~g}$ (mean $0.43 \pm 0.07$ ). There were also highly significant differences between the weights of the pupae of the two sexes. The mean $( \pm \mathrm{SD})$ pupal period (days) of I. sibirica in the asparagus field is presented in Table 2.

Table 2. Mean ( \pm SD) pupal period (days) of I. sibirica in the asparagus field (2009-2011)

\begin{tabular}{lll}
\hline \multirow{2}{*}{ Year } & \multicolumn{2}{c}{ Isoceras sibirica Alpheraky } \\
\cline { 2 - 3 } & $\mathrm{n}$ & Pupal period (days) \\
\hline 2009 & 10 & $20.60 \pm 3.02$ \\
2010 & 14 & $19.79 \pm 4.11$ \\
2011 & 22 & $21.32 \pm 3.46$ \\
\hline
\end{tabular}

n: number of cocoon nests.

\subsection{Adults}

Moths emerged from April through June. On average, mean forewing length was $28.4 \pm 0.80 \mathrm{~mm}$ for females (Figure 2.4) $(\mathrm{n}=187)$, compared to $24.3 \pm 0.67 \mathrm{~mm}$ for males $(\mathrm{n}=198)$. Forewing wingspan was $52.4 \pm 0.83$ $\mathrm{mm}$ and $45.2 \pm 0.89 \mathrm{~mm}$ for females and males, respectively. Highly significant differences were found between the mean length of forewing and the wingspan of the male and the female moths. Mean life span of I. sibirica in the asparagus field is presented in Table 3.

Table 3. Adult lifespan (days) of I. sibirica in the asparagus field (2009-2011)

\begin{tabular}{llllll}
\hline \multirow{2}{*}{ Year } & \multicolumn{4}{c}{ Isoceras sibirica Alpheraky } & \multirow{2}{*}{ t-test } \\
\cline { 2 - 5 } & $\mathrm{n}$ & Male & $\mathrm{n}$ & Famale & \\
\hline 2009 & 69 & $5.72 \pm 2.02$ & 57 & $4.86 \pm 1.56$ & $\mathrm{~ns}$ \\
2010 & 57 & $6.22 \pm 1.74$ & 67 & $5.07 \pm 1.34$ & $* *$ \\
2011 & 78 & $6.95 \pm 2.18$ & 88 & $5.23 \pm 1.43$ & $* *$
\end{tabular}

$\mathrm{n}$ : number of males or females moths; ns: not significant difference between male and female; $* *$ : highly significant difference between male and female.

\subsection{Occurrence of I. sibirica}

Time of occurrence of I. sibirica is listed in Table 4. 
Table 4. Time of occurrence of the various stages of I. sibirica in the asparagus field

\begin{tabular}{|c|c|c|c|c|c|c|c|c|}
\hline Cycle & 1 & 2 & 3 & 4 & 5 & 6 & $7-11$ & 12 \\
\hline Overw & & & & & & & & \\
\hline Larval & & & & & & & & \\
\hline Pupae & & & & & & & & \\
\hline Moths & & & & & & & & \\
\hline Eggs & & & & & & & & \\
\hline
\end{tabular}

\section{Discussion}

Experimental results presented herein have resolved much of the confusion over the timing of $I$. sibirica development (Al-Mehmmady, 2000). Total number of eggs laid varied by a few hundred or more, however, no significant differences $(\mathrm{P}<0.01)$ were found between numbers of eggs from different egg clusters after mating (Figure 2.3). Our results correlate with the work of Guoqi (2008), who reported an average of 226 and noted that incubation periods are dependent on climate. Oviposition can be influenced by many factors, including plant volatiles, secondary chemicals, temperature and waxes on leaf surfaces (Asian Vegetable Research and Development Center, 1986; Lu, Chen, \& Zhu, 1988; Talekar \& Shelton, 1993), however, eggs continue to be laid so long as the temperature is favorable (Gothilf, 1970).

It appears that variations in larvae periods correlate with the availability of food and favorable climatic conditions. The newly emerged larvae are active and roll in the soil looking for food. When they encounter asparagus, the larvae first consume the stem, then the roots, which renders the crop unfit for human consumption. As a result, major reductions in asparagus yield can occur (Guoqi et al., 2008).

Other factors affecting pupation include the thickness of the soil. Previous studies of the time of pupation reported that the average date for eclosion was May 21, but this varied depending upon the temperature (Markin, Nagata, \& Taniguchi, 1989).

Moths remain quiescent due to an aversion to light. The life span of males is longer than that of females. It is possible that females consume too much energy before dying. In addition, some morphological differences exist between the forewing and anterior wing (Figures 2.1 and 2.2).

Additional studies should fully elucidate the biology of I. sibirica and provide information to facilitate the development of more effective control strategies for this pest. Accurate and detailed information regarding the biology of $I$. sibirica is necessary for development of an effective program for management of this important and widespread pest.

Initial data suggest that the application of sex pheromones may be an effective strategy to reduce attacks by $I$. sibirica (Alpheraky), and temper crop damage (C. J. DeLoach, A. D. DeLoach, \& Cordo, 1979). Future work focused on ultrastructural findings of I. sibirica, in relation to the underlying biochemical processes of sex pheromone biosynthesis or plant volatiles, may also prove informative (Yokoyama et al., 2003).

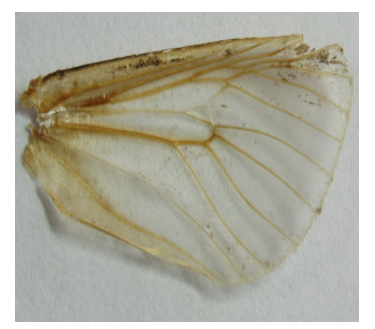

2.1

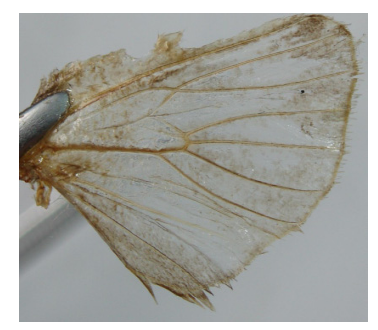

2.2

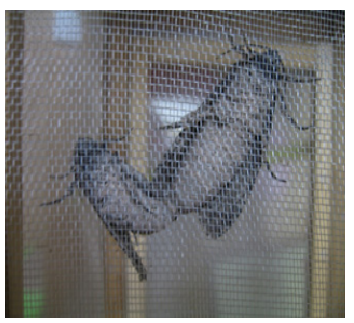

2.3

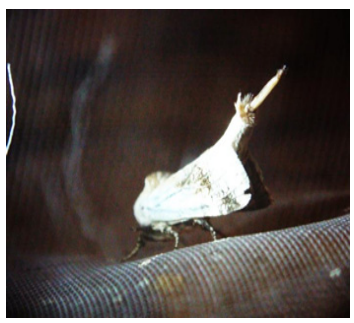

2.4

Figure 2. 2.1 forewing; 2.2 interior wing; 2.3 mating; 2.4 female 


\section{Acknowledgements}

This research was supported by the National $12^{\text {th }}$ Five-year Science and Technology Support Plan of China (Grant no.2012BAD19B07) and the Research Foundation of the Introduction of Talents of Shanxi Agricultural University (Grant no.2014ZZ09).

\section{References}

Al-Mehmmady, R. M. (2000). Biological studies on the okra moth, Earias vittella (F.)(Lepidoptera: Noctuidae) in Jeddah, Saudi Arabia. Research Bulletin, 96, 5-18. Retrieved from http://hdl.handle.net/123456789/7916

Asian Vegetable Research and Development Center. (1986). AVRDC Progress Report Summaries 1985 (p. 96). Shanhua, Taiwan: Asian.

DeLoach, C. J., DeLoach, A. D., \& Cordo, H. A. (1979). Observations on the biology of the moth, Samea multiplicalis, on waterlettuce in Argentina. J. Aquat. Plant Manage, 17, 42-44.

Gaochuan, S., Hongli, Q., Zhanbei, Z., et al. (2013). Main asparagus diseases and pests and key control methods of Pollution-free production in Shanxi Province. Journal of Shanxi Agricultural Sciences, 4(4), $377-380$. http://dx.doi.org/10.3969/j.issn.1002-2481.2013.04.22

Gothilf, S. (1968). The biology of the carob moth Ectoniyelois ceraioniae (Zell.) in Israel. III. Mass culture on artificial diet. Israel J. Ent., 3(2), 109-118.

Gothilf, S. (1970). The biology of the carob moth Ectomyelois ceratoniae (Zell.) in Israel. III. Phenology on various hosts. Israel J. Ent., 5, 161-175.

Guoqi, D., Zhanbei, Z., et al. (2008). The bionomics of Isoceras sibirica. Chinese Bulletin of Entomology, 45(3), 397-400. http://dx.doi.org/10.3969/j.issn.0452-8255.2008.03.012

Guoqi, D., Zhanbei, Z., et al. (2010). Preference of Isoceras sibirica to storage root and stem of asparagus and effects of humidity on development of its pupae. Journal of Environmental Entomology, 32(2), 152-157. http://dx.doi.org/10.3969/j.issn.1674-0858.2010.02.002

Hongxia, L., Yujie, H., \& Jintong, Z. (2010). Study on the Occurrence Regularity and Control Techniques of Isoceras sibirica Alpheraky and Crioceris quatuordecimpunctata Scopolic, Xiandai Nongye Keji, 14, 145-146. http://dx.doi.org/10.3969/j.issn.1007-5739.2010.14.095

Jump-up USDA. (2006). Vegetables 2005 Summary. National Agricultural Statistics Service.

Kioko, E. N., Raina, S. K., \& Mueke, J. M. (2000). Survey on diversity of wild silk moths species in East Africa. East African Journal of Science, 2(1), 1-6.

Lu, Z. Q., Chen, L. F., \& Zhu, S. D. (1988). Studies on the effect of temperature on the development, fecundity and multiplication of Plutella xylostella L. Insect Knowl., 25, 147-149.

Markin, G. P., Nagata, R. F., \& Taniguchi, G. (1989). Biology and behavior of the South American moth, Cyanotricha necyria (Felder and Rogenhofer) (Lepidoptera: Notodontidae), a potential biocontrol agent in Hawaii of the forest weed, Passiflora mollissima (HBK) Bailey. Proc Hawaiian Entomol Soc., 29, 115-123. http://dx.doi.org/ 10.1303/jjaez.27.17

Mbahin, N, Raina, S. K., Kioko, E. N., et al. (2007). Spatial distribution of cocoon nests and egg clusters of the silkmoth Anaphe panda (Lepidoptera: Thaumetopoeidae) and its host plant Bridelia micrantha (Euphorbiaceae) in the Kakamega Forest of western Kenya. International Journal of Tropical Insect Science, 27(3-4), 138-144. http://dx.doi.org/10.1017/S1742758407859662

Mbahin, N., Raina, S. K., Kioko, E. N., \& Mueke, J. M. (2012). Biology of the wild silkmoth Anaphe panda (Boisduval) in the Kakamega forest of Western Kenya. International Journal of Forestry Research, 2012, 186549. http://dx.doi.org/10.1155/2012/186549

Moses, L. E., Emerson, J. D., \& Hosseini, H. (1984). Analyzing data from ordered categories. The New England Journal of Medicine, 311(7), 442-448. http://dx.doi.org/10.1056/NEJM198408163110705

Peacock, L., \& Worner, S. P. (2008). Biological and ecological traits that assist establishment of alien invasive insects. New Zealand Plant Protection, 61, 1-7. Retrieved from http://www.nzpps.org/terms_of_use.html

Schmidt, F. H., Campbell, R. K., \& Trotter, S. J. (1977). Errors in determining instar numbers through head capsule measurements of a lepidoptera - A laboratory study and critique. Annals of the Entomological Society of America, 70(5), 750-756. 
Talekar, N. S., \& Shelton, A. M. (1993). Biology, ecology, and management of the diamondback moth. Annual Review of Entomology, 38(1), 275-301. http://dx.doi.org/10.1146/annurev.en.38.010193.001423

Yokoyama, N., Fónagy, A., Tatsuki, S., et al. (2003). Ultrastructural studies on the pheromone-producing cells in the silkmoth, Bombyx mori: formation of cytoplasmic lipid droplets before adult eclosion. Acta Biologica Hungarica, 54(3), 299-312. http://dx.doi.org/10.1556/ABiol.54.2003.3- 4.8

\section{Copyrights}

Copyright for this article is retained by the author(s), with first publication rights granted to the journal.

This is an open-access article distributed under the terms and conditions of the Creative Commons Attribution license (http://creativecommons.org/licenses/by/3.0/). 